\section{AURANTININ B, A NEW ANTIMICROBIAL ANTIBIOTIC FROM BACTERIAL ORIGIN}

Sir:

During the course of the screening program for new antibiotics from true bacteria, we have found that Bacillus aurantinus Masuma and Ōmura sp. nov. (B. aurantinus KM-214) produced a novel antibiotic, aurantinin $A$ which exhibits biological activity against Gram-positive bacteria and have reported its characterization and biological activity in the previous paper. ${ }^{1,2)}$ Recently, we found that the organism produced a new component, aurantinin B prior to the production of aurantinin A during the fermentation. In this communication, we wish to report the isolation, characterization and biological properties of aurantinin B.

Fermentation was carried out by the same procedure used for aurantinin A., ${ }^{1,2)}$ The culture broth (70 liters) of $B$. aurantinus sp. nov. fermented in a 100-liter tank using a medium consisting of glycerol $1 \%$, starch $1 \%$, soybean meal $2 \%$ dried yeast $0.3 \%, \mathrm{NaCl} 0.5 \%$, $\left(\mathrm{NH}_{4}\right)_{2} \mathrm{SO}_{4} \quad 0.2 \%, \mathrm{~K}_{2} \mathrm{HPO}_{4} 0.1 \%, \mathrm{CaCO}_{3} \quad 0.3 \%$ at $\mathrm{pH} 7.0$ was adjusted to $\mathrm{pH} 2.0$ and centrifuged. The antibiotic was extracted with $n$-butyl acetate from the filtrate. The organic layer was concentrated in vacuo to afford an oily residue which was precipitated with $n$-hexane to give a crude powder $(15 \mathrm{~g})$. The powder was chromatographed on a Sephadex LH-20 column eluted with $\mathrm{MeOH}$ and the combined active fractions were concentrated to dryness to afford a crude powder $(5.5 \mathrm{~g})$. This powder was then applied to centrifugal liquid chromatography in $\mathrm{CHCl}_{3}-\mathrm{MeOH}(30: 1)$ followed by preparative silica gel TLC using $\mathrm{CHCl}_{3}-\mathrm{MeOH}$ $(10: 1)$ to obtain active substance $(1.3 \mathrm{~g})$. Aurantinins $\mathrm{A}$ and $\mathrm{B}$ show $\mathrm{Rf}$ values 0.13 and 0.10 , respectively, on silica gel $\mathrm{TLC}$ in $\mathrm{CHCl}_{3}-\mathrm{MeOH}$ $(10: 1)$. Each component was finally rechromatographed on Sephadex LH-20 to obtain pure aurantinins A (200 mg) and B (118 mg), as yellowish powders. The antibiotics were detected as red spots on silica gel plate after spraying with conc sulfuric acid and also by orange fluorescence on UV irradiation. The physicochemical properties of aurantinin $B$ were as follows: $\mathrm{MP} 98^{\circ} \mathrm{C} ;[\alpha]_{\mathrm{D}}^{25}+124^{\circ}(c 0.33, \mathrm{MeOH})$; UV $\lambda_{\mathrm{max}}^{\mathrm{MeOH}} \mathrm{nm}\left(\mathrm{E}_{\mathrm{lem}}^{106}\right) 268(433), 278(541), 287$
(480), 320 (218); IR (KBr) $\mathrm{cm}^{-1} 3400(\mathrm{OH})$, 1765 (COO), 1725 (CO, COOH, COO), 1082, 1035 (COC). The molecular formula, $\mathrm{C}_{35} \mathrm{H}_{54} \mathrm{O}_{8}$ for aurantinin A was proposed, from electron impact mass spectral (EI-MS) data in a previous paper. ${ }^{2)}$ However, subsequent data, field desorption mass spectra (FD-MS) $\left(m / z 636, \mathrm{M}^{+}\right)$ and EI-MS $\left(m / z 618.358, \mathrm{M}^{+}-\mathrm{H}_{2} \mathrm{O}\right.$, calcd for $\mathrm{C}_{38} \mathrm{H}_{50} \mathrm{O}_{7}, 618.356$ ) for aurantinin $\mathrm{A}$ and FD-MS $\left(m / z 762, \mathrm{M}^{+}\right)$and EI-MS $\left(m / z\right.$ 762.396, $\mathrm{M}^{+}$, calcd for $\mathrm{C}_{44} \mathrm{H}_{58} \mathrm{O}_{11}, 762.397$ ) for triacetyl aurantinin $\mathrm{A}$, led to the revised molecular formula, $\mathrm{C}_{35} \mathrm{H}_{54} \mathrm{O}_{9}$ for the molecular formula for aurantinin A. The molecular formula, $\mathrm{C}_{44} \mathrm{H}_{60} \mathrm{O}_{12}$ of component $\mathrm{B}$ was deduced from the FD-MS data of aurantinin $\mathbf{B}\left(m / z 780, \mathbf{M}^{+}\right)$, a tetraacetate $\left(\mathrm{m} / z\right.$ 948, $\left.\mathrm{M}^{+}\right)$and monomethyl ester $\left(m / z 794, \mathrm{M}^{+}\right)$and its ${ }^{13} \mathrm{C}$ NMR spectrum.

Comparisons of ${ }^{1} \mathrm{H}$ and ${ }^{13} \mathrm{C}$ NMR spectral analyses of aurantinins $\mathrm{A}$ and $\mathrm{B}$ showed that component $\mathrm{B}$ was similar structurally to $\mathrm{A}$. The ${ }^{13} \mathrm{C}$ NMR spectrum $(100 \mathrm{MHz}$, in acetone$d_{6}$ ) of component $\mathrm{B}$ showed the existence of eight methyls, five methylenes, eight methines, seven oxymethines, twelve olefinic carbons, two anhydride carbons, and one carboxyl and one ketone carbonyl carbon, as shown in Fig. 1. The difference ${ }^{13} \mathrm{C}$ spectrum of both components indicated that aurantinin $B$ was a glycoside which is constituted from aurantinin $A$ as an aglycone and a keto sugar possessing the formula, $\mathrm{C}_{8} \mathrm{H}_{10} \mathrm{O}_{5}$ (a ketone carbonyl at $\delta$ 206.5, an anomeric carbon at $\delta 105.1$, three oxygenated carbons at $\delta 78.0,77.8$ and 72.8, and a methyl carbon at $\delta$ 18.4).

Methanolysis of compound $B$ afforded the same product, a monomethyl ester, ( $\mathrm{mp}$ 94 $96^{\circ} ;[\alpha]_{D}^{25}+148^{\circ}(c \quad 0.35$, MeOH $)$; FD-MS $m / z$ $\left.650\left(\mathrm{M}^{+}\right)\right)$as obtained by methylation of $\mathrm{A}$ with $\mathrm{CH}_{2} \mathrm{~N}_{2}$. This means that the aglycone moiety of $\mathbf{B}$ is identical with A. The structure elucidation of aurantinins by NMR analysis and biosynthetic means using ${ }^{18} \mathrm{C}$-labeled precursor deduced a novel polyketide structure with four rings containing a triene and an acid anhydride moiety for aurantinin A which corresponds to the aglycone part of aurantinin B. The structure and biosynthesis of aurantinins will be reported soon in a separate paper. The occurrence of polyketide antibiotic containing a triene as a secondary metabolite of true bacteria is extremely rare. The only reported examples are pro- 
Fig. 1. ${ }^{13} \mathrm{C}$ NMR spectra of aurantinins A and B $\left(100 \mathrm{MHz}\right.$, acetone- $\left.d_{6}\right)$.

(A)

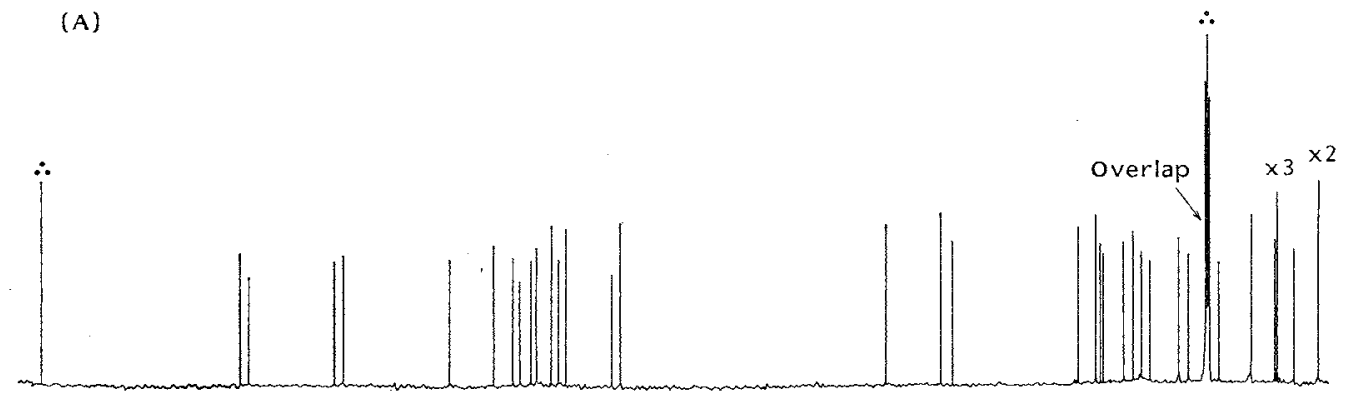

(B)

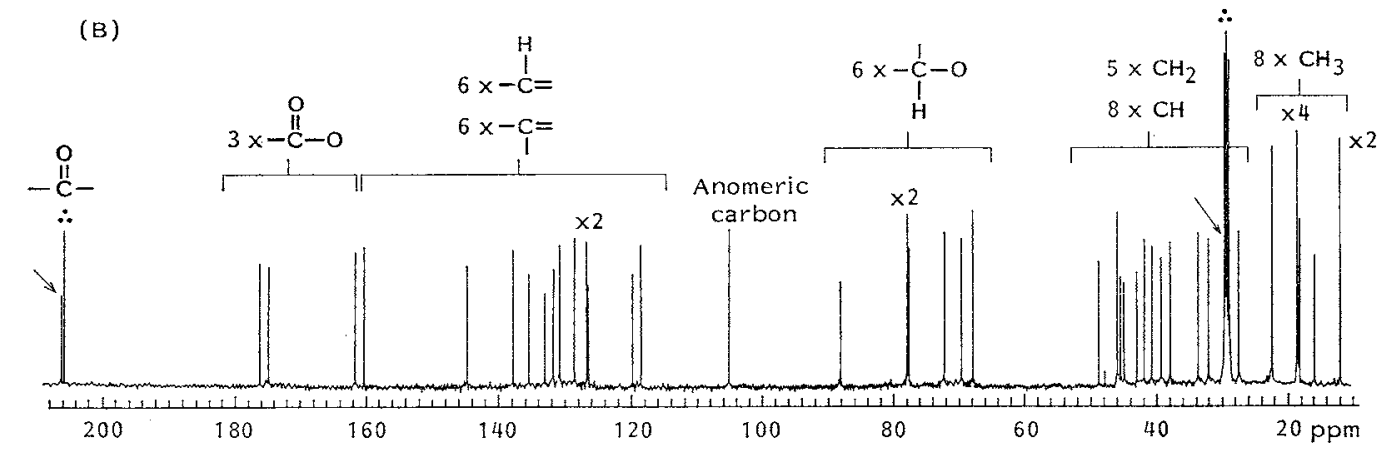

Table 1. Antibacterial activity of aurantinin B against selected aerobes and anaerobes.

\begin{tabular}{|c|c|c|c|}
\hline \multirow[b]{2}{*}{ Organism } & \multicolumn{3}{|c|}{$\mathrm{MIC}(\mu \mathrm{g} / \mathrm{ml})^{*}$} \\
\hline & Aurantinin B & $\begin{array}{l}\text { Erythromycin } \\
\text { gluceptate }\end{array}$ & Cefoxitin \\
\hline Staphylococcus aureus Pens & 4.0 & 0.06 & \\
\hline S. aureus A & 1.0 & 0.06 & \\
\hline Streptococcus pyogenes $\mathbf{E}^{\mathrm{S}}$ & 8.0 & $<0.008$ & \\
\hline S. pyogenes $\mathrm{E}^{\mathrm{R}}$ & 4.0 & $>128.0$ & \\
\hline Corynebacterium pyogenes A & 4.0 & $<0.008$ & \\
\hline Pasteurella haemolytica A & 8.0 & 1.0 & \\
\hline P. multocida A & 4.0 & 0.5 & \\
\hline Clostridium perfringens & $\leq 0.06$ & NT & 0.25 \\
\hline C. ramosum & 0.5 & 1.0 & 32.0 \\
\hline C. difficile $\mathrm{Clin}^{\mathrm{R}}$ & 0.5 & 8.0 & 4.0 \\
\hline Peptostreptococcus anaerobius & 0.5 & NT & 1.0 \\
\hline Bacteroides fragilis & $>128.0$ & 32.0 & 8.0 \\
\hline Fusobacterium mortiferum & $>128.0$ & 16.0 & 32.0 \\
\hline
\end{tabular}

* Agar dilution assay.

Pen: Penicillin, A: animal origin, E: erythromycin, Clin: clindamycin, s: sensitive, ${ }^{\mathrm{R}}$ : resistant.

NT: Not tested.

ticin $^{3,4)}$ and difficidin ${ }^{57}$ and its analog.

Aurantinins exhibit a broad antimicrobial activity against Gram-positive bacteria but not against Gram-negative bacteria, filamentous fungi and yeast. Aurantinin B is more potent than $\mathrm{A}$ in antimicrobial activity. The antimi- crobial activities of aurantinin $\mathrm{B}$ against selected aerobes and anaerobes are shown in Table 1 . The most interesting activities attributable to aurantinin $B$ are those directed against anaerobic bacteria, especially Clostridium perfringens, $C$. ramosum and $C$. difficile in which the activity was 
higher than cefoxitin. Aurantinin B was considerably less active than erythromycin against sensitive Streptococcus pyogenes, but showed good activity against an erythromycin-resistant strain.

\section{Acknowledgments}

The authors are indebted to Dr. D. Hendun of Merck Sharp \& Dohme Research Laboratories for providing the antibacterial data of aurantinin $\mathbf{B}$.

\section{YAEKO KONDA \\ AKIRA NAKAGAWA \\ YOSHIHIRO HARIGAYA \\ MASAYUKI ONDA}

School of Pharmaceutical Sciences, Kitasato University, Minato-ku, Tokyo 108, Japan

\section{ROKURŌ MASUMA SATOSHI ŌMURA*}

The Kitasato Institute, Minato-ku, Tokyo 108, Japan

(Received July 25, 1987)

\section{References}

1) Ōmura, S.; T. Nishikiori, R. Ō'wa, Y. IwaI, R. Masuma \& M. Katagiri: A new antibiotic KM-214 produced by a strain of Bacillus. J. Antibiotics 29: 477 478, 1976

2) Nishikiori, T.; R. Masuma, R. Ōiwa, M. Katagiri, J. Awaya, Y. Iwai \& S. Ōmura: Aurantinin, a new antibiotic of bacterial origin. J. Antibiotics 31: 525 532, 1978

3) PräVe, P.; D. SUKatsch \& L. Vértesy: Proticin, a new phosphorous-containing antibiotic. I. Taxonomy, fermentation, isolation and biological properties. J. Antibiotics 25: $1 \sim 3,1972$

4) Vértesy, L.: Proticin, a new phosphorouscontaining antibiotic. II. Characterization and chemical studies. J. Antibiotics 25: 4 10, 1972

5) Zimmerman, S.B.; E.C. Gilfillan, S. Mochales, R.L. Monaghan, B.A. Pelak, C.D. Schwartz, E. Tejera, K. Wilson, B. Weissberger, M. Zweerink, A. Edison, S. A. Currie \& E. O. STAPLEY: Difficidin and oxydifficidin: Novel broad spectrum, antibacterial antibiotics produced by Bacillus subtilis. Production and antibacterial activity. Program and Abstracts of the 26th Intersci. Conf. on Antimicrob. Agents Chemother., No. 231, p. 138, New Orleans, Sept. $28 \sim$ Oct. 1, 1986 